\title{
Rapid response of habitat structure and above-ground carbon storage to altered fire regimes in tropical savanna
}

\author{
Shaun R. Levick ${ }^{1,2,3}$, Anna E. Richards², Garry D. Cook ${ }^{2}$, Jon Schatz ${ }^{2}$, Marcus Guderle ${ }^{1}$, Richard J. Williams ${ }^{2}$, \\ Parash Subedi $^{3}$, Susan E. Trumbore ${ }^{1}$, and Alan N. Andersen ${ }^{3}$ \\ ${ }^{1}$ Max Planck Institute for Biogeochemistry, Hans-Knoell-Str. 10, 07745 Jena, Germany \\ ${ }^{2}$ CSIRO Land and Water, PMB 44, Winnellie, Darwin 0822 NT, Australia \\ ${ }^{3}$ Research Institute for the Environment and Livelihoods, Charles Darwin University, Casuarina NT 0909, Australia
}

Correspondence: Shaun R. Levick (shaun.levick@csiro.au)

Received: 13 April 2018 - Discussion started: 27 April 2018

Revised: 8 February 2019 - Accepted: 5 March 2019 - Published: 10 April 2019

\begin{abstract}
Fire regimes across the globe have been altered through changes in land use, land management, and climate conditions. Understanding how these modified fire regimes impact vegetation structure and dynamics is essential for informed biodiversity conservation and carbon management in savanna ecosystems. We used a fire experiment at the Territory Wildlife Park (TWP), northern Australia, to investigate the consequences of altered fire regimes for vertical habitat structure and above-ground carbon storage. We mapped vegetation three-dimensional (3-D) structure in high spatial resolution with airborne lidar across 18 replicated 1 ha plots of varying fire frequency and season treatments. We used lidar-derived canopy height and cover metrics to extrapolate field-based measures of woody biomass to the full extent of the experimental site $\left(R^{2}=0.82, \mathrm{RMSE}=7.35 \mathrm{tC} \mathrm{ha}^{-1}\right)$ and analysed differences in above-ground carbon storage and canopy structure among treatments. Woody canopy cover and biomass were highest in the absence of fire $(76 \%$ and $39.8 \mathrm{t} \mathrm{Cha}^{-1}$ ) and lowest in plots burnt late in the dry season on a biennial basis ( $42 \%$ and $18.2 \mathrm{t} \mathrm{Cha}^{-1}$ ). Woody canopy vertical profiles differed among all six fire treatments, with the greatest divergence in height classes $<5 \mathrm{~m}$. The magnitude of fire effects on vegetation structure varied along the environmental gradient underpinning the experiment, with less reduction in biomass in plots with deeper soils. Our results highlight the large extent to which fire management can shape woody structural patterns in savanna landscapes, even over time frames as short as a decade. The structural profile changes shown here, and the quantification of carbon reduction under late dry season burning, have important im-
\end{abstract}

plications for habitat conservation, carbon sequestration, and emission reduction initiatives in the region.

\section{Introduction}

Fire is an integral component of the functioning of savanna ecosystems, exerting top-down control on woody vegetation structure (Bond and Keeley, 2005; Sankaran et al., 2005). Savanna fires restrict vegetation vertical growth through a "fire-trap" mechanism, whereby young trees are constrained to low woody re-sprouts under high fire frequencies (Higgins et al., 2000; Freeman et al., 2017). A lengthening of the fire-free interval allows trapped woody plants to grow above flame height, enabling them to reach mid- and upper-canopy heights, with long-term consequences for size-class distribution and structural heterogeneity (Helm and Witkowski, 2012; Levick et al., 2015a).

Three-dimensional (3-D) heterogeneity of vegetation has long been valued as a key factor promoting faunal diversity through increased niche diversity and availability (MacArthur and MacArthur, 1961; MacArthur, 1964). The structural modifications that fires impart on savanna vegetation have been shown to impact both vertebrate (Woinarski et al., 2004) and invertebrate (Andersen et al., 2012) taxa. Fire-driven structural changes to savanna vegetation also have important implications for climate regulation, as savanna fires contribute significantly to atmospheric emissions of greenhouse gases through biomass combustion (Hurst et al., 1994; van der Werf et al., 2010). Despite the impor- 
tance of quantifying fire-induced changes to 3-D structure in savanna vegetation, current understanding of magnitudes and spatial patterns remains limited, and savanna fires represent large uncertainty in global vegetation models (Higgins et al., 2007; Scheiter et al., 2013). Gaining better understanding of how different fire regimes impact savanna vegetation structure is becoming increasingly urgent in the face of changing climate and land-management conditions that are triggering variations in the timing, frequency, intensity, and duration of fires in the tropical biome (Alencar et al., 2015).

Fire frequency in Australian savannas is particularly high, with many regions burning twice in every 3 years on average (Beringer et al., 2014). Many of these fires occur late in the dry season, producing high-intensity burns that result in simplified vegetation structure (Bowman et al., 1988; Lehmann et al., 2009; Ondei et al., 2017). There are widespread concerns that such fire regimes are linked to dramatic declines in faunal populations, through the removal of ground layer vegetation (Lawes et al., 2015; Legge et al., 2015; Woinarski et al., 2015). Methane and nitrous oxide emissions from savanna fires are included in Australia's national greenhouse gas accounts and are responsible for approximately $3 \%$ of total accountable greenhouse gas emissions (Meyer et al., 2012). There is considerable interest in reducing the frequency and intensity of fires in northern Australia through strategic early dry season (April to July) burning in order to reduce both greenhouse gas emissions and certain components of biodiversity decline (Russell-Smith et al., 2013). As such, the Australian government has implemented legislation enabling landowners to claim carbon credits for reducing greenhouse gas emissions from savanna fires through early dry season burning (Carbon Farming Initiative - Emissions Abatement through Savanna Fire Management Methodology Determination 2015, Department of Environment and Energy). Such changes to fire regimes in northern Australia are also likely to increase carbon sequestration in the landscape (Murphy et al., 2010; Richards et al., 2012), although there is currently no approved methodology for incorporating this into the national accounts. While much attention is currently being given to reducing the extent and frequency of late season fires in northern Australia, it is important to recognize that savannas have evolved with fire (Bond and Keeley, 2005; Durigan and Ratter, 2016) and excluding fire would be detrimental to certain savanna specialists that favour more open and grassy habitat. The challenge is finding the best mix of patches of different regimes across connected landscapes.

Understanding of how different fire regimes impact habitat structure and carbon dynamics in tropical savannas can be enhanced through detailed 3-D measurements of vegetation structure at sites subject to long-term, replicated experimental fire treatments. Traditional field-based inventory techniques are limited in their ability to quantify 3-D structure, but light detection and ranging (lidar) can now achieve this with high accuracy and precision in a repeatable and transferable manner (Lefsky et al., 2002; Levick and Rogers, 2008).
Airborne lidar has a proven record in providing detailed 3-D representations of savanna vegetation structure across time and space (Smit et al., 2010; Levick et al., 2012, 2015b; Goldbergs et al., 2018) but has yet to be used for assessing vegetation biomass and structural diversity responses to experimental fires in savannas.

Northern Australia has a long history of savanna fire experiments (Williams et al., 2003), including the ongoing "Burning for Biodiversity" experiment at the Territory Wildlife Park that has applied six fire treatments in three replicated blocks since 2004 (Scott et al., 2010). Here we integrate field-based measurements of vegetation structure with airborne lidar to determine how variation in fire frequency and season affects the 3-D habitat structure and above-ground carbon storage of woody vegetation. Our specific aims are to (i) explore how vegetation carbon storage and structural diversity respond to increasing fire frequency and (ii) quantify the structural impact of late-season fires compared to early season fires. We use airborne lidar data to provide greater spatial coverage than can be achieved with field sampling alone and to gain better understanding of how reliably lidar could be used to assess savanna carbon dynamics in instances where field data may not be available or attainable.

\section{Methods}

\subsection{Study site and experimental design}

The Territory Wildlife Park is located $40 \mathrm{~km}$ south of Darwin in Australia's Northern Territory (Fig. 1). The vegetation at the site is a mixed open forest and woodland savanna dominated by Eucalyptus miniata A.Cunn. ex Shauer, Eucalyptus tetrodonta F.Muell., and Corymbia bleeseri (Blakely) K.D.Hill and L.A.S.Johnson, with a grassy understorey dominated by Pseudopogonatherum contortum (Brongn.) A.Camus, Sarga intrans F.Muell. ex Benth., and Eriachne triseta Nees ex Steud (Scott et al., 2010). The soils are relatively shallow (0.5 to $1 \mathrm{~m}$ deep) gravelly red earths (petroferric red Kandosol) (Isbell, 2002) of the Kay land system within the Koolpinyah land surface group and have developed predominantly from deeply weathered sandstones, siltstones, and shales (Wood et al., 1985). The climate is wetdry tropical with greater than $90 \%$ of annual rainfall (mean $1401 \mathrm{~mm}$ ) falling in the wet season from November to April, and mean monthly maximum and minimum temperatures between 33.1 and $20.9^{\circ} \mathrm{C}$ (Bureau of Meteorology, Commonwealth of Australia).

The fire experiment consists of 181 ha plots grouped into three blocks (A, B, C) arranged along a north-south transect (Fig. 1). Soils are deeper at the southern end, and the $C$ block has higher soil moisture given its proximity to a small drainage line. Six fire treatments were randomly assigned to each block at the start of the experiment: unburnt plots (U); plots burnt at fire return intervals of 1 (E1), 2 (E2), 3 (E3), 


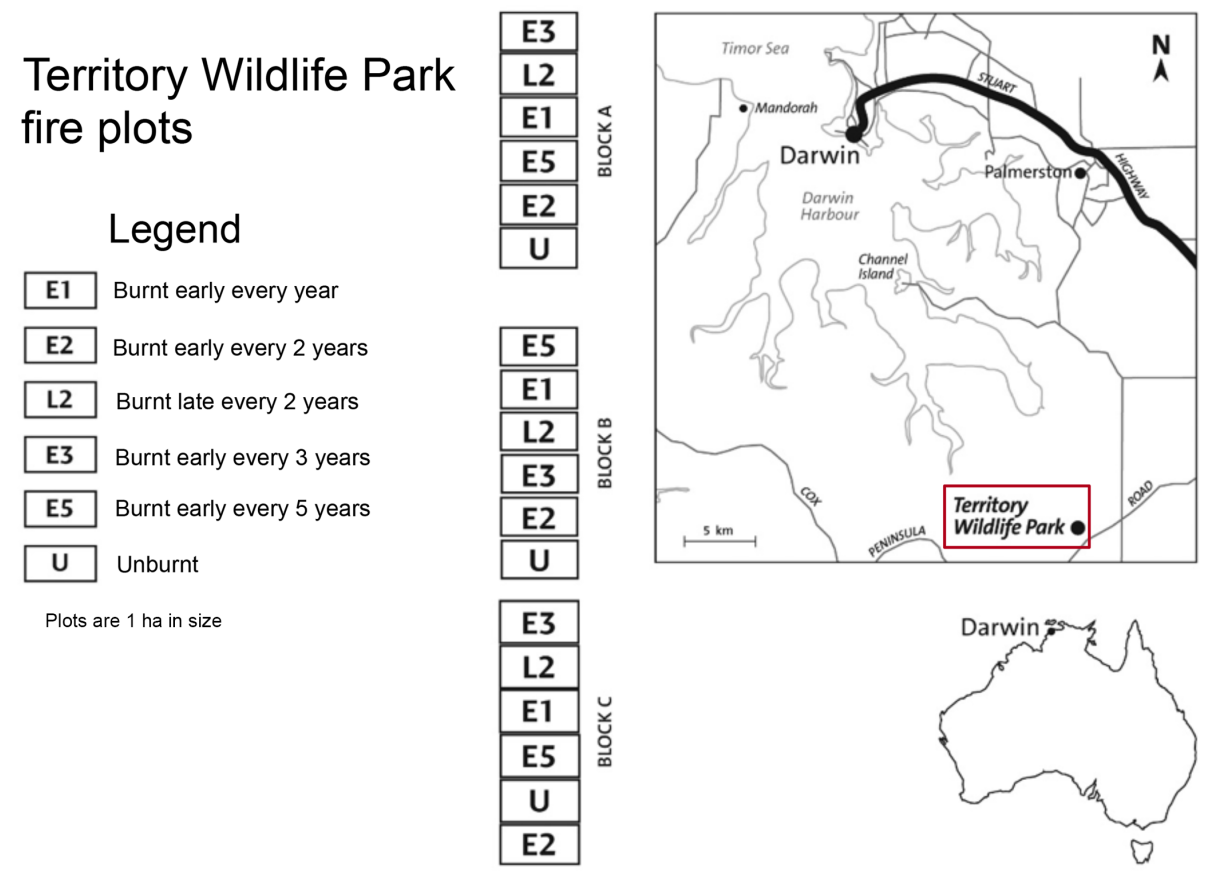

Figure 1. Location and experimental design of the Territory Wildlife Park fire manipulation experiment. Treatments were fist implemented in 2004. Soil depth and soil moisture increase from the northern to southern blocks.

and 5 (E5) years in the early dry season (E2); and plots burnt every 2 years (L2) in the late dry season (Table 1). Prior to implementation of the burning treatments in 2004, all areas had been unburnt for at least 14 years when fire records started (except for a fire in 1992 and again in 2000 in the A block only).

During each experimental burn, fire intensity was estimated using the established relationship between rate of spread and fuel load (Williams et al., 1998). Rate of fire spread was determined from thermocouples positioned $5 \mathrm{~cm}$ above the soil surface in the flaming combustion zone, linked to buried electronic stop watches. Six timers were used in each 1 ha plot, arranged in a series of equilateral triangles, with $10 \mathrm{~m}$ sides. The rate of fire spread was also determined by observers using stop watches, manually recording the time of arrival at the points where the electronic watches were positioned. All points were marked by star pickets and flagging tape. Fuel loads were determined prior to each fire by direct harvest and weighing. A total of 10 replicate $0.5 \mathrm{~m} \times 0.5 \mathrm{~m}$ fuel samples were cut for each plot. Fuel heat content was assumed to be $20000 \mathrm{~kJ} \mathrm{~kg}^{-1}$ dry weight.

\subsection{Field-based estimation of above-ground woody biomass}

In each of the 18 plots, two $30 \mathrm{~m} \times 30 \mathrm{~m}$ subplots were established at the north-west and south-east corners, at least $10 \mathrm{~m}$ away from plot edges. In each subplot the species identity, location, height, and diameter of all woody plants $>2 \mathrm{~m}$ in height were recorded. The location of each individual plant was recorded to $0.3 \mathrm{~m}$ accuracy using a differential GPS with post-processing (Trimble Inc.). Tree heights were recorded with a standard height pole (plants $<8 \mathrm{~m}$ ) or clinometer (plants $>8 \mathrm{~m}$ ), and stem diameter was recorded at $1.3 \mathrm{~m}$ with a diameter tape for all woody species except for the multi-stemmed shrubs Calytrix exstipulata and Exocarpos latifolius, in which case diameter was recorded at the stem base ( $0.1 \mathrm{~m}$ above the ground). Above-ground biomass was calculated for each individual tree using the equation developed by Williams et al. (2005):

$\ln \mathrm{ABG}=-2.0596+2.1561(\ln D)+0.1362(\ln H)^{2}$,

whereby AGB is above-ground biomass $(\mathrm{kg}), D$ is stem diameter $(\mathrm{m})$, and $H$ is tree height $(\mathrm{m})$. Individual tree biomasses were then summed for each $30 \mathrm{~m} \times 30 \mathrm{~m}$ subplot. Estimated biomass values were converted to carbon terms on a per hectare basis assuming $50 \%$ of biomass was carbon $\left(\mathrm{tCha}^{-1}\right)$. This approach did not consider the contribution of small $(<2 \mathrm{~m})$ multi-stemmed shrubs to the carbon pool.

\subsection{Airborne lidar surveying and processing}

We mapped 150 ha of the study area with airborne lidar in June 2013, 9 years after the start of the experiment. The airborne survey was conducted by Airborne Research Australia (ARA) with a full-waveform lidar sensor (RIEGL LMSQ560) operated from a light fixed-wing aircraft (Diamond Aircraft ECO Dimona). Flight lines with $>50 \%$ overlap 
Table 1. Fire regime characteristics of the Territory Wildlife Park experimental site. Data are for the period 2004-2013. Fire intensity values are the mean and standard error over the course of the experiment.

\begin{tabular}{llrrr}
\hline Treatment & Season & Frequency (year) & Intensity $\left(\mathrm{kW} \mathrm{m}^{-1}\right)$ & Times burnt \\
\hline E1 & June & 1 & $589 \pm 144$ & 9 \\
E2 & June & 2 & $929 \pm 20$ & 4 \\
E3 & June & 3 & $424 \pm 26$ & 3 \\
E5 & June & 5 & $295 \pm 69$ & 2 \\
L2 & October & 2 & $1644 \pm 131$ & 5 \\
U & n/a & 0 & 0 & 0 \\
\hline
\end{tabular}

n/a - not applicable

were used to achieve double coverage of the plots (average flying height $300 \mathrm{~m}$ a.g.l., swath width $250 \mathrm{~m}$, line spacing $125 \mathrm{~m}$ ), and the RIEGL LMS-Q560 was operated at $240 \mathrm{kHz}$ and 135 lines per second. Slow flying speed of less than $40 \mathrm{~m} \mathrm{~s}^{-1}$ ensured high point densities along track, with an average return density of $22.28 \mathrm{~m}^{2}$ and an average pulse spacing of $0.21 \mathrm{~m}$.

Raw lidar data were processed with RiANALYZE (RIEGL Laser Measurement Systems $\mathrm{GmbH}$ ) for decomposing the full waveforms into discrete returns. The ARA RASP opensource software (RASP version 0.98: manual, code, and executables available from ARA on request) was used to orientate the point cloud to Cartesian coordinates and output the geolocated point cloud in the American Society for Photogrammetry and Remote Sensing (ASPRS) standard LAS format. All further point-cloud processing tasks were conducted with the LAStools suite of processing scripts (Rapidlasso $\mathrm{GmbH}$ ). The last returns were classified into ground and non-ground points for bare-earth extraction. A digital terrain model (DTM) was constructed from ground returns using a triangulated irregular network approach (TIN) at $0.25 \mathrm{~m}$ resolution. The DTM was used to normalize the $z$ coordinate of vegetation returns to height above ground level (Fig. 2).

\subsection{Upscaling above-ground woody biomass estimates with airborne lidar}

The normalized airborne lidar returns were clipped to the spatial extent of each field-measured $30 \mathrm{~m} \times 30 \mathrm{~m}$ subplot. Using the lascanopy tool within LAStools, we extracted a suite of 14 ecologically meaningful metrics describing vegetation structure from the point cloud: mean canopy height $(\mathrm{MCH})$, quadratic mean canopy height $(\mathrm{QMCH})$, canopy cover $>1 \mathrm{~m}$ (COV1), canopy cover $>10 \mathrm{~m}$ (COV10), canopy density (DENS), kurtosis (KUR), skewness (SKE), standard deviation (SDE), canopy relief ratio (CRR), and a series of height quantiles $\left(Q_{10}, Q_{25}, Q_{50}, Q_{75}, Q_{90}\right)$. Using these 14 metrics as explanatory variables, we ran step-wise multiple linear regression with Akaike information criterion (AIC) minimization against the field-estimated biomass to identify the variables with the most explanatory power and used them to construct a lidar-based biomass model. We applied the most robust model (in terms of explanatory power and RMSE) across the full extent of the airborne lidar coverage to examine the effects of fire treatment on above-ground woody biomass.

\subsection{Assessment of treatment effects}

We digitally distributed six $30 \mathrm{~m} \times 30 \mathrm{~m}$ subplots in each fire plot for statistical comparison of treatment effects. We used a linear mixed-effect modelling approach, with Gaussian residual variance, to test the significance of fire treatment on woody canopy cover, canopy height, and aboveground biomass. The models were implemented in $\mathrm{R}$ ( $\mathrm{R}$ Core Team, 2018) with the nlme package (Pinheiro et al., 2018). Maximum likelihood (ML) was used to fit the models, with subplots included as a random effect nested within fire treatments. Fixed effects were fire treatment (E1, E2, E3, E4, E5, L2, U), block position (A, B, C), and the interaction between fire treatment and block position. Models were generated for all possible combinations of fixed effects, together with a null model consisting of only the random effects of the quadrat locations. Akaike information criterion (AIC) scores for each of the models were compared to identify the most parsimonious model.

The impact of fire treatment on vegetation vertical profile distribution was explored by plotting the mean and $95 \%$ confidence interval of lidar returns per $0.5 \mathrm{~m}$ height class. Statistical significance of treatment effects was tested pairwise on a per height class basis using a paired $t$ test.

\section{Results}

\subsection{Estimation of above-ground woody biomass from airborne lidar}

Airborne lidar proved valuable for upscaling woody biomass measurements from the field plots to the full extent of the fire experiment (Fig. 3). Only three woody canopy structural variables were retained in the step-wise linear regression procedure: mean canopy height $(\mathrm{MCH})$, total canopy cover $(\operatorname{Cov} 1 \mathrm{~m})$, and overstorey canopy cover (Cov10m): 


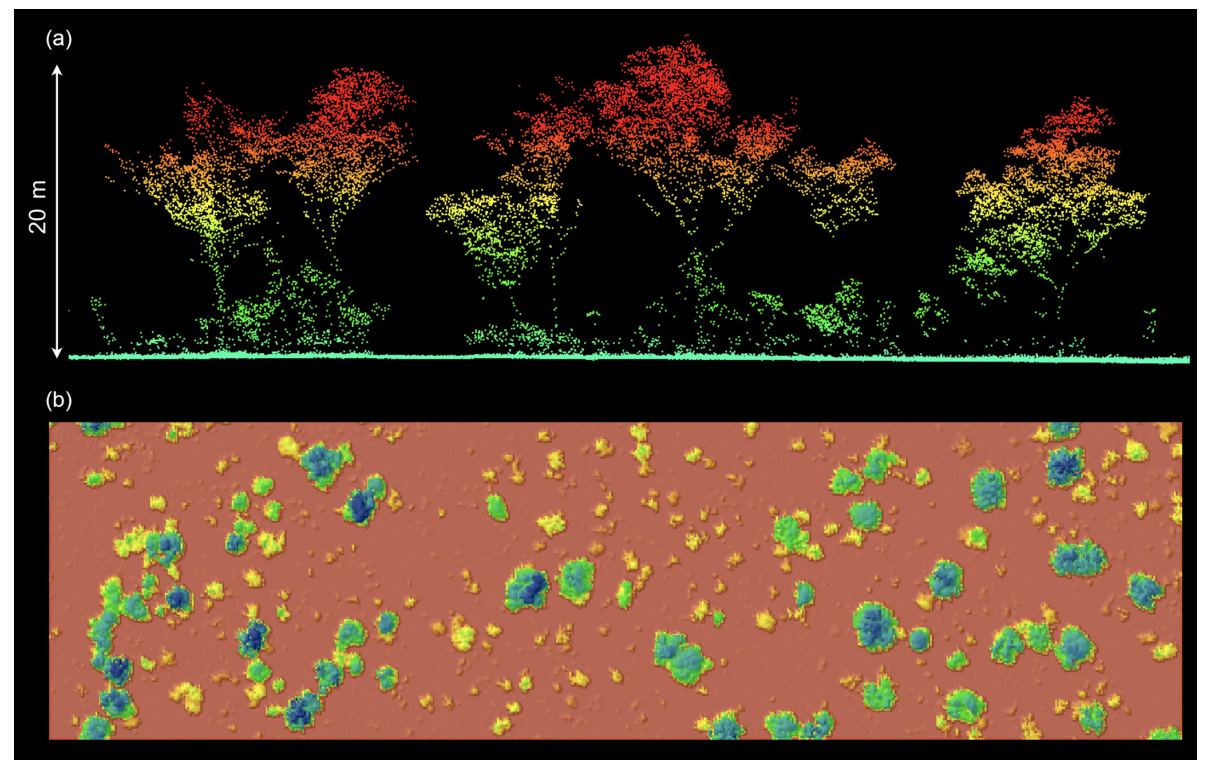

Figure 2. Cross section through the normalized high-resolution lidar point cloud (a) and aerial view of rasterized canopy height model (CHM) interpolation (b). The lidar point cloud provided excellent representation of both the vertical and horizontal structures of vegetation across the site.

$$
\begin{aligned}
\mathrm{AGB} & =-6.524+(-0.794 \operatorname{Cov} 10 \mathrm{~m})+(-0.345 \operatorname{Cov} 1 \mathrm{~m}) \\
& +(14.881 \mathrm{MCH}) .
\end{aligned}
$$

The distribution of model residuals showed no spatial trend or relationship with the fire treatment. The degree of residual error $\left(\mathrm{RMSE}=7.35 \mathrm{tC} \mathrm{ha}^{-1}\right)$ provided acceptable confidence for inclusion of modelled biomass values in further analyses.

\subsection{Effects of fire regime on woody canopy cover and above-ground biomass}

Canopy cover decreased along the experimental gradient of fire frequency and season, ranging from about $75 \%$ $(\mathrm{SE}=1.7)$ in unburnt plots to $45 \%(\mathrm{SE}=2.3)$ in late season biennial plots (Fig. 4a). These differences in canopy cover translated into similar patterns of biomass variation across the experiment (Fig. 4b). The highest within-treatment variability for both cover and biomass was found in the early season annual plots (E1).

The best model explaining variation in both woody cover and biomass was one in which fire treatment, block position, and the interaction between them was included (Table 2). Model performance was poorer when the interaction term was excluded $(\triangle \mathrm{AIC}=48.91,32.98$, and 39.29 for woody cover, height, and biomass respectively). When explanatory variables were considered independently, fire treatment was more influential than block position on variation in woody cover $(\triangle \mathrm{AIC}=70.25$ vs. 90.67$)$, but not for mean canopy height ( $\triangle \mathrm{AIC}=59.96$ vs. 48.93 ) or woody biomass

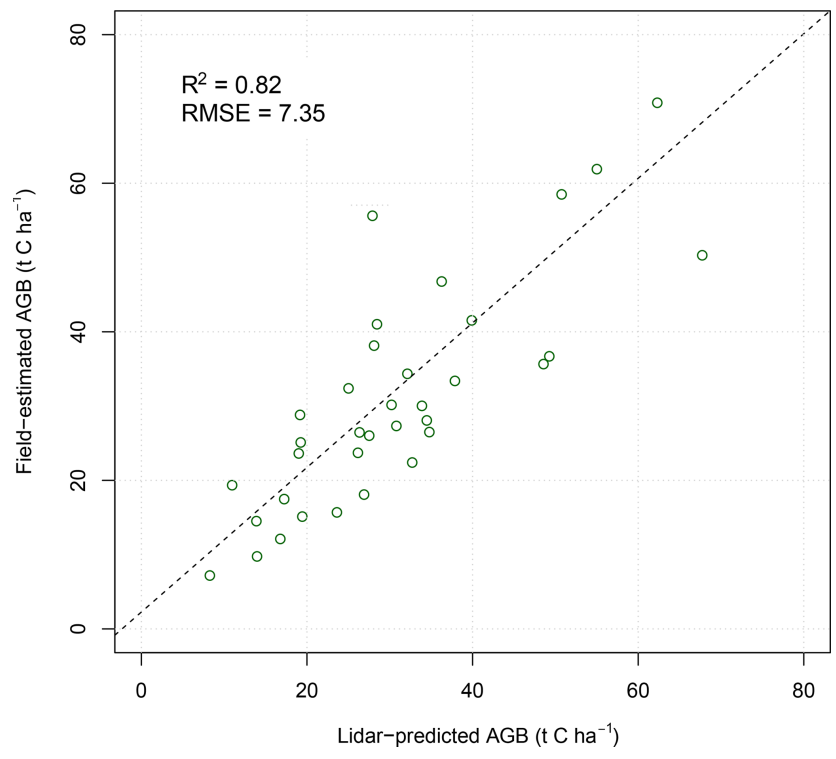

Figure 3. Relationship between field-estimated above-ground biomass and estimates predicted from airborne lidar metrics. Open green circles represent individual subplots $(30 \mathrm{~m} \times 30 \mathrm{~m})$; the dashed line shows the linear fit.

$(\triangle \mathrm{AIC}=73.34$ vs. 51.70$)$. These results point to an important source of environmental variation arising from block position, which represents a gradient in soil depth and moisture availability across the experimental site.

When we consider the spectrum of increasing fire intensity occurring across the experimental treatments, we found that correlations between the reductions in above-ground biomass 
Table 2. Linear mixed model results of lidar-estimated canopy cover, mean height, and above-ground woody biomass.

\begin{tabular}{lrrrrrr}
\hline Model terms & AIC cover & $\Delta$ AIC cover & AIC height & $\Delta$ AIC height & AIC biomass & $\Delta$ AIC biomass \\
\hline Fire treatment $\cdot$ block & 806.14 & 0.00 & 406.47 & 0.00 & 864.51 & 0.00 \\
Fire treatment + block & 855.05 & 48.91 & 439.45 & 32.98 & 903.81 & 39.29 \\
Fire treatment & 876.59 & 70.45 & 466.43 & 59.96 & 937.87 & 73.34 \\
Block & 896.81 & 90.67 & 455.40 & 48.93 & 916.23 & 51.70 \\
Null model & 915.34 & 109.20 & 477.03 & 70.56 & 944.09 & 79.57 \\
\hline
\end{tabular}

and fire intensity decreased along the soil depth and moisture availability gradient (Fig. 5). In carbon terms, the early biennial fires on average caused a reduction of $10 \mathrm{tCha}^{-1}$ compared to unburnt plots, whereas late biennial fires almost doubled that reduction to $19 \mathrm{tC} \mathrm{ha}^{-1}$.

\subsection{Fire effects on vertical habitat structure}

In addition to the observed patterns in woody canopy cover and above-ground biomass, our lidar-based assessment also revealed substantial variation in canopy height profile distributions, derived from the number of lidar returns from different height levels (Fig. 6). Most profiles were bimodal, with a peak at 1-2 $\mathrm{m}$ in height and a smaller peak at $10-15 \mathrm{~m}$. The clearest bimodal response was found in the early season triennial burns (Fig. 6c), whereas early season annual and 5year burn profiles were more uniform (Fig. 6a, d).

Keeping fire frequency constant (biennial) and exploring the effects of fire season highlighted the large influence of late season versus early season burns (Fig. 7a). Compared with no fire, early season biennial fires significantly reduced canopy below $5.5 \mathrm{~m}$ and late season biennial fire reduced canopy even further up to the $9.5 \mathrm{~m}$ height class $(p<0.05$, Fig. 7b), generating a vertical profile similar in shape but with lower frequency of occurrence. The late season fire profile contained significantly less canopy in nearly all height classes compared to the unburnt ( $p<0.05$, Fig. 7a, b), but the most marked effects were in the lower height classes, which represent the shrub layer and the recruitment zone.

\section{Discussion}

Airborne lidar provided direct measures of canopy cover and height distribution, and the derived metrics successfully predicted field-based estimates of above-ground biomass. The synoptic view that airborne lidar provided enabled us to map changes in biomass under different fire regimes, in addition to exploring differences in vegetation vertical profiles across the full expanse of the fire experiment.

\subsection{Carbon storage consequences of altered fire regimes}

A total of 10 years of experimental burning imparted large structural differences in woody canopy across the plots of the Territory Wildlife Park fire experiment. Fire effects were most pronounced at the extremes of the experimental spectrum, with the highest cover and biomass occurring under complete fire exclusion and the lowest values of woody canopy structure obtained under biennial late season burning. The directionality of these trends was persistent across the underlying gradient of increasing soil depth and moisture, but the magnitude and slope of the effects was greater in the A and B blocks with shallower, drier soils (Fig. 5). The lower magnitude of carbon reduction in the lower-lying $\mathrm{C}$ block likely stems from the sparse herbaceous cover in these plots, which results in patchy, low-intensity fires.

Recent research into woody biomass trends in the region (from long-term field monitoring plots) indicate that woody biomass has been relatively stable over decadal periods, with minor evidence of woody thickening, and that biomass is negatively correlated with fire frequency (Murphy et al., 2013). However, as Fensham et al. (2017) note, a key finding emerging from that regional study was that the observed decreases in tree biomass following severe fires were not driven by mortality of individual trees, but rather by decreases in the rates of biomass accumulation of surviving trees. We do not have repeated individual tree data in our study to directly corroborate this finding, but the patterns of reduced cover throughout the height profile do suggest mortality and the consumption of trees by fire, rather than just reduction in growth rates.

Similar investigations in southern African savannas have found that fire frequency itself had little bearing on woody cover, but that the presence of fire alone was a stronger predictor of reduced woody cover (Devine et al., 2015). In our study, however, we found that cover and biomass were reduced as fire frequency increased (Fig. 4), with the exception to the trend being the early biennial fires (E2), which had a slightly larger impact on structure than the early annual (E1) fires. The experimental design incorporates fire frequency and season, but the net result of these components of the fire regime is fire intensity, which is the stronger determining factor of vegetation structural change (Williams et al., 1999; Furley et al., 2008). Of all the fire treatments, the biennial burns had the highest mean intensities of 929 and $1664 \mathrm{~kW} \mathrm{~m}^{-1}$ for early season and late season fire respectively. These intensities are still low compared to those of large late season fires in northern Australia and reflect 
(a)

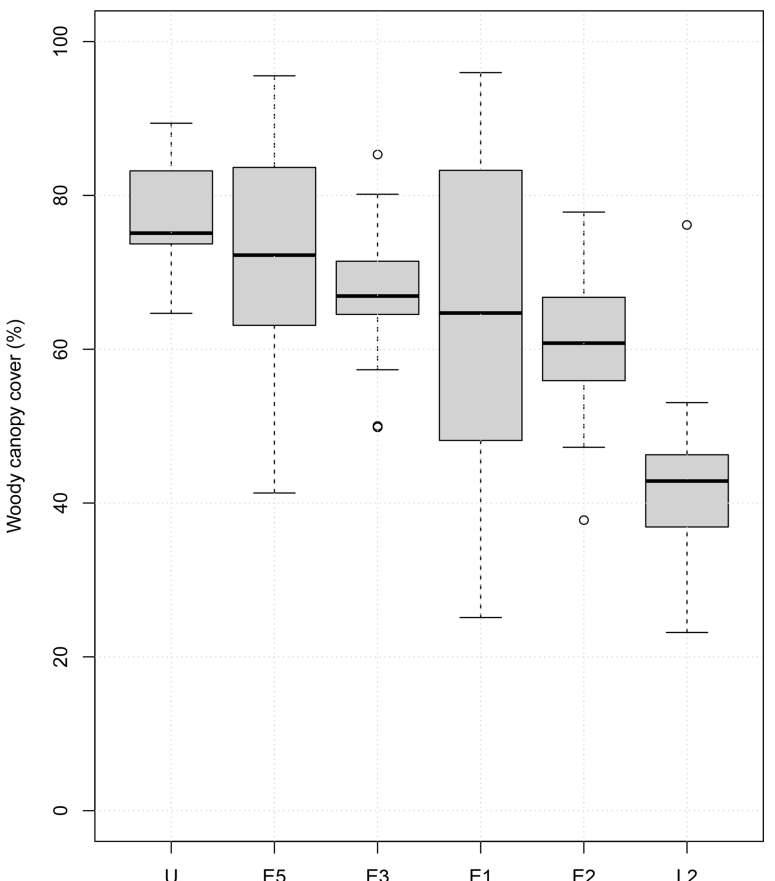

(b)

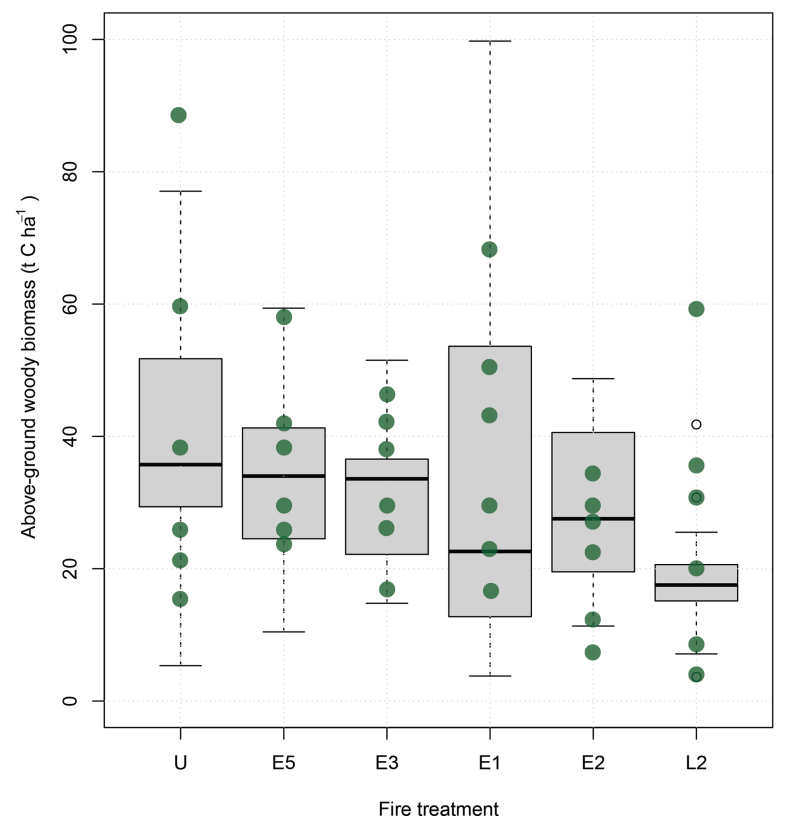

Figure 4. Relationship between fire treatments and (a) woody canopy cover and (b) woody biomass. Fire treatments ordered according to increasing fire intensity. Green dots in (b) indicate fieldmeasured values derived from $30 \mathrm{~m} \times 30 \mathrm{~m}$ subplots.

the small scale of the experimental plots. Nonetheless, despite lower intensities across the board compared to larger experiments like those obtained at the Kapalga experiment, our findings are in agreement with the diminished basal areas observed there under very-high-intensity late season fires (Andersen et al., 2003).

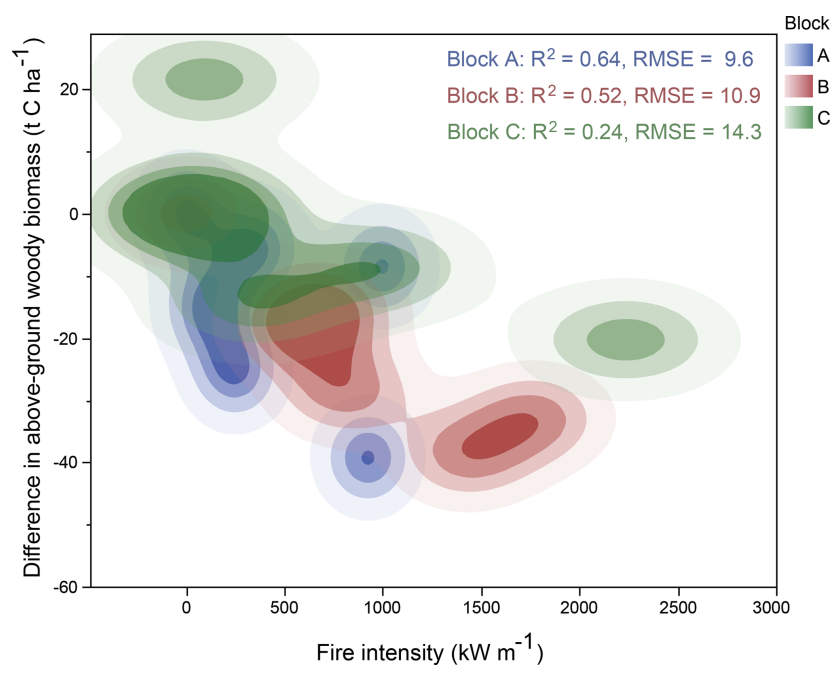

Figure 5. Density plot showing the relationship between increasing fire intensity reduction in woody carbon storage, relative to unburnt plots, for the A (blue), B (red), and C (green) blocks.

There is increasing interest in understanding the effect of different fire regimes on carbon stored in Australian savannas (Murphy et al., 2013; Cook et al., 2015) and recent studies have shown higher carbon stocks in dead organic matter under lower fire frequencies (Cook et al., 2016). At the Territory Wildlife Park fire plots the early biennial fire caused a reduction of $10 \mathrm{tC} \mathrm{ha}^{-1}$ on average compared to unburnt plots, whereas late biennial fires almost doubled that average reduction to $19 \mathrm{tC} \mathrm{ha}^{-1}$ (Fig. 5). These patterns are consistent with the trend of lower greenhouse gas emissions under early dry season fires, relative to late fires (Meyer et al., 2012), and point to the importance of available fuel load and its characteristics (greater herbaceous volume and lower moisture content late in the dry season) in understanding fire-induced structural change in savannas. This is further emphasized by the variation in response to fire along the environmental gradient of the experimental site.

Murphy et al. (2013) suggested that the moderation of fire regimes in northern Australia is likely to increase carbon storage in woody biomass, but the extent to which woody biomass can increase in these savannas is highly uncertain. Our results reduce some of this uncertainty, by providing quantification of the degree to which carbon stored in unburnt plots deviates from a range of different fire frequencies.

\subsection{Shifts in vegetation vertical profile distribution under altered fire regimes}

Different fire regimes imparted a diverse array of vertical structural profiles on woody vegetation. Although woody canopy cover and above-ground biomass displayed subtle responses among the early season fire frequency treatments, we found that each fire regime generated a relatively unique niche space in terms of vertical profile distribution. These 
(a) Early season 1-year

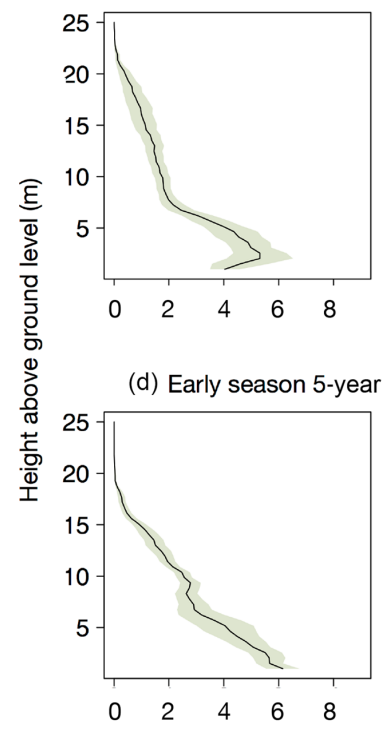

(b) Early season 2-year

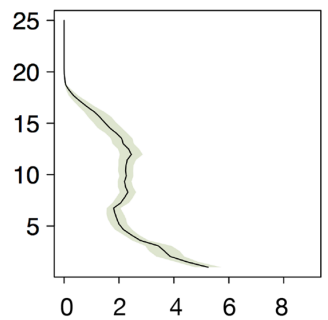

(e) Late season 2-year

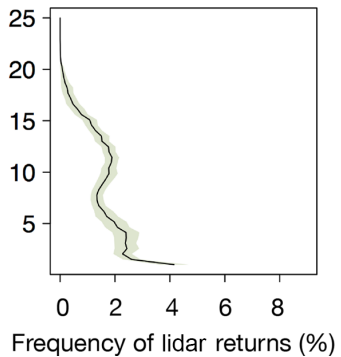

(c) Early season 3-yea

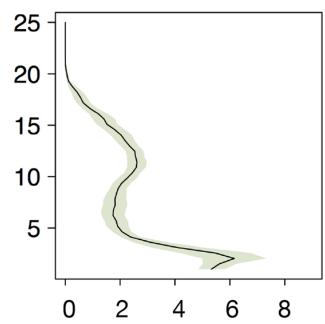

(f) Unburnt

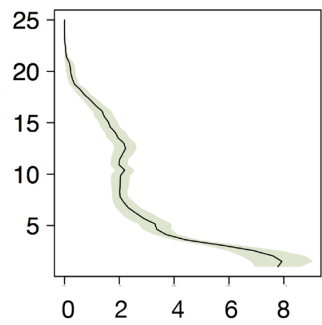

Figure 6. Effects of fire regime on vertical habitat structure determined from the frequency of airborne lidar returns. Solid black lines are the mean frequency distribution of lidar returns, and the green bands indicate the $95 \%$ confidence interval.

(a)

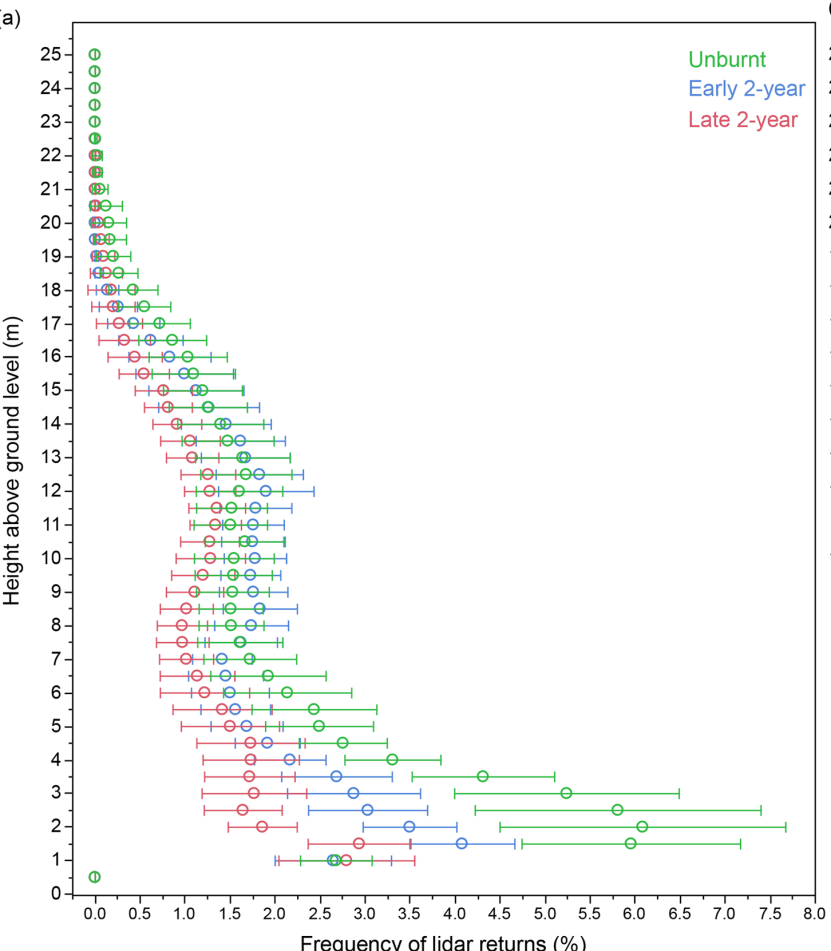

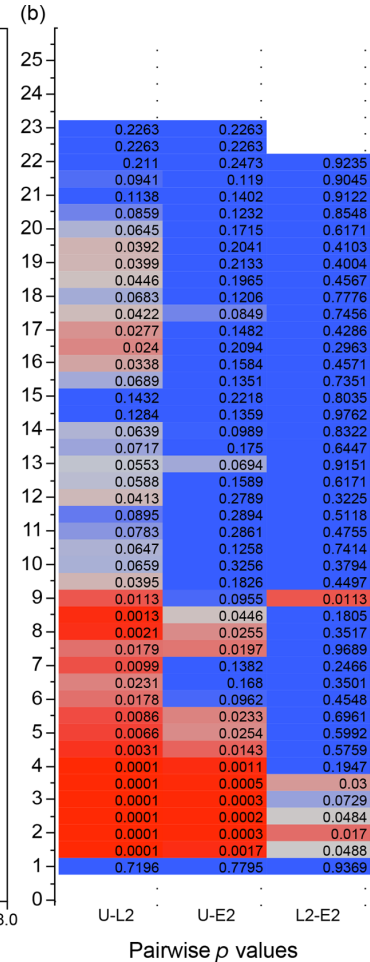

Figure 7. Effect of biennial fire season on woody vertical profile structure with unburnt treatment in green, early season biennial in blue, and late season biennial in red. (a) Dots and error bars represent the mean and $95 \%$ confidence interval for the $30 \mathrm{~m} \times 30 \mathrm{~m}$ subplots $(n=18)$. Some returns from lower height classes may have arisen from herbaceous material. (b) Pairwise comparison of differences in means on a per height class basis. U-L2 is unburnt vs. late season biennial, U-E2 is unburnt vs. early season biennial, and L2-E2 is late season vs. early season biennial. $p$ values are shaded with values $<0.05$ in red. 
niches were most divergent in the understorey height classes $(<5 \mathrm{~m})$. Tracking these profiles over time into the future might reveal increased height of divergence as cohorts grow taller. Alternatively, these understorey height curves may represent stable persistent equilibrium re-sprout heights that define the optimum for re-sprouts that are able to persist within the flame zone under a particular fire regime (Freeman et al., 2017).

These vertical profile findings highlight the powerful role that fire management can play in shaping three-dimensional habitat structure in ecosystems. The challenge this presents to land managers is deciding which of this range of profiles is optimal for their specific management objectives. We still lack explicit understanding of how different organisms utilize three-dimensional space, and it is increasingly evident that no one profile is optimal. Mid-storey shrubs and trees provide key food resources for birds and small mammals, and high ground cover reduces predation risk by feral cats (Davies et al., 2016). Conversely, habitat simplification through late season burning was found to promote longer-term abundance of frilled-neck lizards in Kakadu National Park, despite high initial direct mortality rates (Corbett et al., 2003; Andersen et al., 2005). As such, it is likely that a mix of patches at the landscape scale, spanning a diverse range of vertical profiles, is needed from a wildlife conservation perspective. The relative proportions and spatial arrangement of these patches needs targeted and deeper investigation.

\subsection{Limitations and future directions}

Our findings in this study provide quantification of the magnitudes of fire regime effects on woody structure in a tropical savanna. When generalizing to other savanna regions however, the following limitations should be to be taken into consideration. First, prior to the establishment of the TWP fire experiment in 2004 the vegetation was unburnt since 1990. In these tropical landscapes 14 years of fire exclusion is rare, so the starting conditions are atypical.

Second, despite the good results obtained in upscaling field-based woody biomass estimates with airborne lidar (Fig. 3), future efforts should focus on reducing the level of uncertainty in the lidar biomass model. Greater confidence in biomass and carbon prediction could be achieved by turning to individual tree-based segmentation approaches. Developments in terrestrial lidar in particular show great promise for providing individual tree volumes and biomass estimates that can be scaled, together with their uncertainties, to plot and landscape scales (Calders et al., 2014; Levick et al., 2016; Singh et al., 2018). Furthermore, the rich 3-D models that terrestrial lidar provide will open up new avenues for exploring actual 3-D structural metrics.

Last, our analyses in this study rely on differences between treatments at a single point in time to infer the mechanisms underpinning woody structural modification. Although typical for this type of investigation, the single-time-point ap- proach should ideally be complimented with time-series analyses of before and after fire events to better constrain the mechanisms underpinning structural change.

\section{Conclusions}

We quantified the magnitude of above-ground carbon reduction under different regimes by integrating airborne lidar, field surveys, and an ongoing fire regime experiment. Our results highlight the impact of late season burning on both carbon storage and canopy vertical profile structure. Clear relationships between biodiversity and fire regimes have proven difficult to establish in savannas, despite many attempts at linking floral and faunal diversity directly to fire regime patterns. The range of vertical profile responses that we have illustrated here under different experimental fire treatments could hold the key to unlocking stronger links between fire management and biodiversity responses. High-resolution lidar can expose the structural consequences of different management actions and make them more easily accessible for integration with biodiversity and ecosystem process studies.

Data availability. Data are accessible via the CSIRO Data Portal (https://data.csiro.au/dap, last access: 2 April 2019).

Author contributions. SRL, AER, GDC, SET, and ANA conceived the study. JS, PS, and AER conducted the field research. RJW and JS collected the fire intensity data. SRL and MG processed the lidar data and conducted the analyses. All authors contributed to the writing of the paper.

Competing interests. The authors declare that they have no conflict of interest.

Acknowledgements. This project was jointly funded through CSIRO, Charles Darwin University, and the Australian Government's National Environmental Science Programme (NESP). We acknowledge the Northern Territory Government and the Territory Wildlife Park for establishing and maintaining the long-term fire experimental site. Jorg Hacker and Airborne Research Australia (ARA) are thanked for their airborne surveying of the site. Shaun R. Levick was supported by grant number 01DR14010 from the BMBF (FIREBIODIV project).

The article processing charges for this open-access publication were covered by the Max Planck Society.

Review statement. This paper was edited by Christopher Still and reviewed by three anonymous referees. 


\section{References}

Alencar, A. A., Brando, P. M., Asner, G. P., and Putz, F. E.: Landscape fragmentation, severe drought, and the new Amazon forest fire regime, Ecol. Appl., 25, 1493-1505, 2015.

Andersen, A. N., Cook, G. D., and Williams, R. J. (Eds.): Fire in tropical savannas: the Kapalga experiment, Springer-Verlag, New York, USA, https://doi.org/10.1007/b97225, 2003.

Andersen, A. N., Cook, G. D., Corbett, L. K., Douglas, M. M., Eager, R. W., Russel-Smith, J., Setterfield, S. A., Williams, R. J., and Woinarski, J. C. Z.: Fire frequency and biodiversity conservation in Australian tropical savannas: implications from the Kapalga fire experiment, Austral. Ecol., 30, 155-167, https://doi.org/10.1111/j.1442-9993.2005.01441.x, 2005.

Andersen, A. N., Woinarski, J. C. Z., and Parr, C. L.: Savanna burning for biodiversity: Fire management for faunal conservation in Australian tropical savannas, Austral Ecol., 37, 658-667, 2012.

Beringer, J., Hutley, L. B., Abramson, D., Arndt, S. K., Briggs, P., Bristow, M., Canadell, J. G., Cernusak, L. A., Eamus, D., Edwards, A. C., Evans, B. J., Fest, B., Goergen, K., Grover, S. P., Hacker, J., Haverd, V., Kanniah, K., Livesley, S. J., Lynch, A., Maier, S., Moore, C., Raupach, M., Russell-Smith, J., Scheiter, S., Tapper, N. J., and Uotila, P.: Fire in Australian savannas: from leaf to landscape, Glob. Change Biol., 21, 62-81, 2014.

Bond, W. and Keeley, J.: Fire as a global "herbivore": the ecology and evolution of flammable ecosystems, Trends Ecol. Evol., 20, 387-394, 2005.

Bowman, D. M. J. S., Wilson, B. A., and Hooper, R. J.: Response of Eucalyptus Forest and Woodland to Four Fire Regimes at Munmarlary, Northern Territory, Australia, J. Ecol., 76, 215-232, https://doi.org/10.2307/2260465, 1988.

Calders, K., Newnham, G., Burt, A., Murphy, S., Raumonen, P., Herold, M., Culvenor, D., Avitabile, V., Disney, M., Armston, J., and Kaasalainen, M.: Nondestructive estimates of above-ground biomass using terrestrial laser scanning, Methods Ecol. Evol., 6, 198-208, 2014

Cook, G. D., Liedloff, A. C., Cuff, N. J., Brocklehurst, P. S., and Williams, R. J.: Stocks and dynamics of carbon in trees across a rainfall gradient in a tropical savanna, Austral Ecol., 40, 845856, 2015

Cook, G. D., Meyer, C. P. M., Muepu, M. L., and Liedloff, A. C.: Dead organic matter and the dynamics of carbon and greenhouse gas emissions in frequently burnt savannas, Int. J. Wildland Fire, 25, 1252-1263, 2016.

Corbett, L. K., Andersen, A. N., and Müller, W. J.: Terrestrial vertebrates, in: Fire in tropical savannas: the Kapalga experiment, edited by: Andersen, A. N., Cook, G. D., Williams, R. J., Springer-Verlag, New York, USA, 126-152, https://doi.org/10.1007/b97225, 2003.

Davies, H. F., McCarthy, M. A., Firth, R. S. C., Woinarski, J. C. Z., Gillespie, G. R., Andersen, A. N., Geyle, H. M., Nicholson, E., and Murphy, B. P.: Top-down control of species distributions: feral cats driving the regional extinction of a threatened rodent in northern Australia, Divers. Distrib., 23, 272-283, 2016.

Devine, A. P., Stott, I., McDonald, R. A., and Maclean, I. M. D.: Woody cover in wet and dry African savannas after six decades of experimental fires, J. Ecol., 103, 473-478, 2015.

Durigan, G. and Ratter, J. A.: The need for a consistent fire policy for Cerrado conservation, J. Appl. Ecol., 53, 11-15, 2016.
Fensham, R. J., Freeman, M. E., Laffineur, B., Macdermott, H., Prior, L. D., and Werner, P. A.: Variable rainfall has a greater effect than fire on the demography of the dominant tree in a semiarid Eucalyptus savanna, Austral Ecol., 42, 772-782, 2017.

Freeman, M. E., Vesk, P. A., Murphy, B. P., Cook, G. D., Richards, A. E., and Williams, R. J.: Defining the fire trap: Extension of the persistence equilibrium model in mesic savannas, Austral Ecol., 42, 890-899, 2017.

Furley, P. A., Rees, R. M., Ryan, C. M., and Saiz, G.: Savanna burning and the assessment of long-term fire experiments with particular reference to Zimbabwe, Prog. Phys. Geogr., 32, 611-634, 2008.

Goldbergs, G., Levick, S. R., Lawes, M., and Edwards, A.: Hierarchical integration of individual tree and area-based approaches for savanna biomass uncertainty estimation from airborne LiDAR, Remote Sens. Environ., 205, 141-150, https://doi.org/10.1016/j.rse.2017.11.010, 2018.

Helm, C. V. and Witkowski, E. T. F.: Characterising wide spatial variation in population size structure of a keystone African savanna tree, Forest Ecol. Manag., 263, 175-188, 2012.

Higgins, S. I., Bond, W. J., and Trollope, W. S. W.: Fire, resprouting and variability: a recipe for grass-tree coexistence in savanna, J. Ecol., 88, 213-229, 2000.

Higgins, S. I., Bond, W. J., February, E. C., Bronn, A., EustonBrown, D. I. W., Enslin, B., Govender, N., Rademan, L., O'Regan, S., Potgieter, A. L. F., Scheiter, S., Sowry, R., Trollope, L., and Trollope, W. S. W.: Effects of four decades of fire manipulation on woody vegetation structure in Savanna, Ecology, 88, 1119-1125, 2007.

Hurst, D. F., Griffith, D. W. T., and Cook, G. D.: Trace gas emissions from biomass burning in tropical Australian savannas, J. Geophys. Res.-Atmos., 99, 16441-16456, 1994.

Isbell, R. F.: The Australian Soil Classification, CSIRO Publishing, Collingwood, 2002.

Lawes, M. J., Murphy, B. P., Fisher, A., Woinarski, J. C. Z., Edwards, A. C., and Russell-Smith, J.: Small mammals decline with increasing fire extent in northern Australia: evidence from longterm monitoring in Kakadu National Park, Int. J. Wildland Fire, 24, 712-722, 2015.

Lefsky, M., Cohen, W., Parker, G., and Harding, D.: Lidar Remote Sensing for Ecosystem Studies, BioScience, 52, 19-30, 2002.

Legge, S., Garnett, S., Maute, K., Heathcote, J., Murphy, S., Woinarski, J. C. Z., and Astheimer, L.: A Landscape-Scale, Applied Fire Management Experiment Promotes Recovery of a Population of the Threatened Gouldian Finch, Erythrura gouldiae, in Australia's Tropical Savannas, PLoS ONE, 10, e0137997, https://doi.org/10.1371/journal.pone.0137997, 2015.

Lehmann, C. E. R., Prior, L. D., and Bowman, D. M. J. S.: Fire controls population structure in four dominant tree species in a tropical savanna, Oecologia, 161, 505-515, 2009.

Levick, S. R. and Rogers, K. H.: Structural biodiversity monitoring in savanna ecosystems: Integrating LiDAR and high resolution imagery through object-based image analysis, in: Object-based image analysis: spatial concepts for knowledge-driven remote sensing applications, edited by: Blaschke, T., Lang, S., and Hay, G., 477-492, Springer-Verlag, Berlin, 2008.

Levick, S. R., Asner, G. P., and Smit, I. P. J.: Spatial patterns in the effects of fire on savanna vegetation three-dimensional structure, Ecol. Appl., 22, 2110-2121, 2012. 
Levick, S. R., Baldeck, C. A., and Asner, G. P.: Demographic legacies of fire history in an African savanna, Funct. Ecol., 29, 131139, 2015a.

Levick, S. R., Setterfield, S., Rossiter-Rachor, N., Hutley, L., MacMaster, D., and Hacker, J.: Monitoring the Distribution and dynamics of an invasive grass in tropical savanna using airborne LiDAR, Remote Sens., 7, 5117-5132, https://doi.org/10.3390/rs70505117, 2015b.

Levick, S. R., Hessenmöller, D., and Schulze, E.-D.: Scaling wood volume estimates from inventory plots to landscapes with airborne LiDAR in temperate deciduous forest, Carbon Balance and Management, 11, 7, https://doi.org/10.1186/s13021-016-0048-7, 2016.

MacArthur, R. H.: Environmental factors affecting bird species diversity, Am. Nat., 98, 387-397, 1964.

MacArthur, R. H. and MacArthur, J. W.: On bird species diversity, Ecology, 42, 594-598, 1961.

Meyer, C. P., Cook, G. D., Reisen, F., Smith, T. E. L., Tattaris, M., Russell-Smith, J., Maier, S. W., Yates, C. P., and Wooster, M. J.: Direct measurements of the seasonality of emission factors from savanna fires in northern Australia, J. Geophys. Res., 117, D20305, https://doi.org/10.1029/2012JD017671, 2012.

Murphy, B. P., Russell-Smith, J., and Prior, L. D.: Frequent fires reduce tree growth in northern Australian savannas: implications for tree demography and carbon sequestration, Glob. Change Biol., 16, 331-343, 2010.

Murphy, B. P., Lehmann, C. E. R., Russell-Smith, J., and Lawes, M. J.: Fire regimes and woody biomass dynamics in Australian savannas, J. Biogeogr., 41, 133-144, 2013.

Ondei, S., Prior, L. D., Williamson, G. J., Vigilante, T., and Bowman, D. M. J. S.: Water, land, fire, and forest: Multi-scale determinants of rainforests in the Australian monsoon tropics, Ecol. Evol., 7, 1592-1604, 2017.

Pinheiro, J., Bates, D., DebRoy, S., Sarkar, D., and R Core Team: nlme: Linear and Nonlinear Mixed Effects Models, available at: https://CRAN.R-project.org/package=nlme (last access: 7 January 2019), r package version 3.1-137, 2018.

Richards, A. E., Andersen, A. N., Schatz, J., Eager, R., Dawes, T. Z., Hadden, K., Scheepers, K., and van der Geest, M.: Savanna burning, greenhouse gas emissions and indigenous livelihoods: Introducing the Tiwi Carbon Study, Austral Ecol., 37, 712-723, 2012.

Russell-Smith, J., Monagle, C., Jacobsohn, M., Beatty, R. L., Bilbao, B., Millán, A., Vessuri, H., and Sánchez-Rose, I.: Can savanna burning projects deliver measurable greenhouse emissions reductions and sustainable livelihood opportunities in fire-prone settings?, Climatic Change, 140, 47-61, 2013.

Sankaran, M., Hanan, N. P., Scholes, R. J., Ratnam, J., Augustine, D. J., Cade, B. S., Gignoux, J., Higgins, S. I., Le Roux, X., Ludwig, F., Ardo, J., Banyikwa, F., Bronn, A., Bucini, G., Caylor, K. K., Coughenour, M. B., Diouf, A., Ekaya, W., Feral, C. J., February, E. C., Frost, P. G. H., Hiernaux, P., Hrabar, H., Metzger, K. L., Prins, H. H. T., Ringrose, S., Sea, W., Tews, J., Worden, J., and Zambatis, N.: Determinants of woody cover in African savannas, Nature, 438, 846-849, 2005.
Scheiter, S., Langan, L., and Higgins, S. I.: Next-generation dynamic global vegetation models: learning from community ecology, New Phytol., 198, 957-969, 2013.

Scott, K. A., Setterfield, S. A., Douglas, M. M., and Andersen, A. N.: Fire tolerance of perennial grass tussocks in a savanna woodland, Austral Ecol., 35, 858-861, 2010.

Singh, J., Levick, S. R., Guderle, M., Schmullius, C., and Trumbore, S. E.: Variability in fire-induced change to vegetation physiognomy and biomass in semi-arid savanna, Ecosphere, 9, e02514, https://doi.org/10.1002/ecs2.2514, 2018.

Smit, I. P. J., Asner, G. P., Govender, N., Kennedy-Bowdoin, T., Knapp, D. E., and Jacobson, J.: Effects of fire on woody vegetation structure in African savanna, Ecol. Appl., 20, 1865-1875, 2010 .

van der Werf, G. R., Randerson, J. T., Giglio, L., Collatz, G. J., Mu, M., Kasibhatla, P. S., Morton, D. C., DeFries, R. S., Jin, Y., and van Leeuwen, T. T.: Global fire emissions and the contribution of deforestation, savanna, forest, agricultural, and peat fires (1997-2009), Atmos. Chem. Phys., 10, 11707-11735, https://doi.org/10.5194/acp-10-11707-2010, 2010.

Williams, R., Gill, A., and Moore, P.: Seasonal changes in fire behaviour in a tropical savanna in northern Australia, Int. J. Wildland Fire, 8, 227-239, 1998.

Williams, R. J., Cook, G. D., Gill, A. M., and Moore, P. H. R.: Fire regime, fire intensity and tree survival in a tropical savanna in northern Australia, Austral Ecol., 24, 50-59, 1999.

Williams, R. J., Woinarski, J. C. Z., and Andersen, A. N.: Fire experiments in northern Australia: contributions to ecological understanding and biodiversity conservation in tropical savannas, Int. J. Wildland Fire, 12, 391-402, 2003.

Williams, R. J., Zerihun, A., Montagu, K. D., Hoffman, M., Hutley, L. B., and Chen, X.: Allometry for estimating aboveground tree biomass in tropical and subtropical eucalypt woodlands: towards general predictive equations, Aust. J. Bot., 53, 607-619, 2005.

Woinarski, J. C. Z., Risler, J., and Kean, L.: Response of vegetation and vertebrate fauna to 23 years of fire exclusion in a tropical Eucalyptus open forest, Northern Territory, Australia, Austral Ecol., 29, 156-176, 2004.

Woinarski, J. C. Z., Burbidge, A. A., and Harrison, P. L.: Ongoing unraveling of a continental fauna: Decline and extinction of Australian mammals since European settlement, P. Natl. Acad. Sci. USA, 112, 4531-4540, 2015.

Wood, B. G., Fogarty, P. J., and Day, K. J.: The land systems of the Darwin region, Northern Territory Conservation Commission, Northern Territory Conservation Commision, Darwin, NT, Australia, available at: http://hdl.handle.net/10070/227809 (last access: 4 April 2019), 1985 